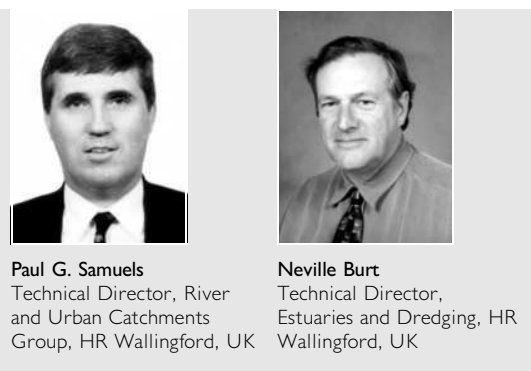

\title{
A new joint probability appraisal of flood risk
}

\section{P. G. Samuels and N. Burt}

Prior to the construction of the Cardiff Bay Barrage the risk of flooding of the Cardiff Bay waterfront was from inundation by surge tides. The barrage has substantially eliminated the probability of tidal flooding, and the residual flood risk now depends upon the ability of the inland bay to provide sufficient storage for river floodwater during periods of high tide. In the course of the feasibility and design studies the actual reduction in flood hazard was not quantified, but the design was carried out against specific combinations of tidal levels and fluvial flows.

Recent research for MAFF at HR Wallingford has now made viable the assessment of the actual degree of flood risk, where flooding depends on the combination of two or more events. This paper presents a new joint probability appraisal of the standard of flood defence for the land around the inland bay, and demonstrates the conservatism incorporated in the original design methodology for flood risks. An examination of individual floods and surge tides and of the daily flow and tide records for a concurrent 18-year period has shown no positive correlation between concurrent high tides and river floods. An ISIS flow model of the Rivers Taff and Ely, the inland bay and the operation of the barrage structure was used to identify combinations of hydro-meteorological events that give specific levels in the inland bay. A statistical frequency assessment of these levels in the inland bay has provided 'return periods' for the still water level in the inland bay exceeding, for example, 7.5 $\mathrm{m}$ OD and $8.0 \mathrm{~m}$ $O D$. This frequency assessment was undertaken for sea levels with and without an allowance for future rise in mean sea level attributable to global warming. The ISIS modelling contained some conservative assumptions, notably the assumed coincidence between the peak of the river flow and high tide in the Bristol Channel, and the effect of these assumptions was investigated by some sensitivity tests. Finally, a best estimate of the return period for these levels in the inland bay was made using the sensitivity testing and the results of a study in 1994 of the effects of the operation of the barrage. It is concluded that the construction of the barrage is a significant flood defence benefit to Cardiff, which now has greater protection from flooding from the inland bay than the Thames Barrier provides for London. Flood risk from impoundment of the inland bay for the waterfront area remains very low even for the currently used scenarios for mean sea level rise due to global warming to the year 2100 .

\section{INTRODUCTION}

\section{I.I. Background}

Prior to the construction of the Cardiff Bay Barrage the risk of flooding of the Cardiff Bay waterfront was from inundation by surge tides. The barrage has substantially eliminated the probability of tidal flooding, and the residual flood risk now depends upon the ability of the inland bay to provide sufficient storage for river floodwater during periods of high tide. This storage is important during periods of 'tide locking' when the barrage sluices are closed to keep the tide out of the inland bay.

Naturally, a key concern at the planning stage was that the Cardiff Bay Barrage should not increase flood risks, and the design was engineered to provide a substantial reduction of the flood hazard in the developed area of the inland bay compared with that in the pre-barrage situation. At the time of its promotion and design, the standard applied to assess the flood hazard after impoundment of the inland bay was based upon hypothetical combinations of river floods and storm tides. These combinations were similar to those used for the design of the earlier Cardiff flood relief scheme along the River Taff. However, there was no assessment of the frequency of occurrence of the levels produced by these design events in the inland bay, as at that time such assessments, though technically possible, were very expensive to undertake. The recent development of the joint probability software JOIN-SEA by HR Wallingford, ${ }^{1}$ under a research contract for MAFF (now DEFRA), and the increase in computing power available since the feasibility and design studies, now make quantification of the flood hazard practicable.

After the impoundment of the inland bay, the key determinants of the system are:

(a) river flood flows and tidal levels in joint combination

(b) storage volume in the inland bay

(c) the threshold level at which inundation of the development will occur

(d) the discharge capacity of the sluices

(e) the mode of operation of the sluices.

The actual flood risks in Cardiff are thus determined by the interaction of the hydro-meteorological forcing (that is, river flow tide and surge levels) with the operation of the barrage sluices. 


\section{I.2. Objective}

The objective of this new assessment was to estimate the standard of flood defence in the inland bay once the Cardiff Bay Barrage was in operation. The assessment was made assuming that the barrage operates as designed and did not consider risks associated with the failure of the barrage or its infrastructure or with flooding from surge tides and waves overtopping the Cardiff flood defences away from the barrage. The exceedance probabilities were assessed for current (that is, circa 1990) sea levels and scenarios for changed hydrometeorological conditions in 2030, 2050 and 2100, characterised by a rise in mean sea level.

\section{I.3. Approach}

There are four ways of assessing the flood risks to the waterfront area after the impoundment of the inland bay:

(a) simulation of the operation of the barrage for a concurrent long time series of observations, and statistical analysis of the results

(b) generation of synthetic time series for tides and river flows, continuous simulation of the operation of the barrage, and analysis of results

(c) formal joint probability analysis of the water levels in the inland bay produced by the interaction of tides, river flows and the operation of the sluices, assuming a form (or lack) of dependence between the flows and tides

(d) random, so-called 'Monte Carlo' sampling using simulated events and potentially correlated frequencies of occurrence of the tides and river flows.

The first option was not feasible because of the lack of sufficient concurrent data.

The study by HR Wallingford ${ }^{2}$ in 1994 with a modified version of the GIBGATE software used the second approach. The concurrent data series constructed for instantaneous tidal and river flow conditions was about 22 years long, and so this frequency analysis should not be extrapolated above about the 50-year return period. The construction of the data series was based upon the long-term tidal record at Avonmouth, mean daily flows for the Rivers Taff and Ely, and a separate extraction of the river discharges for the highest floods in the record. Clearly the length of this reconstructed record, only 22 years, is insufficient for assessing the frequency of the high levels in the inland bay that might cause inundation of the waterfront area (return period in excess of 1000 years). However, it does provide a useful indication of the conservatism in the assumptions made in the current analysis.

The third option was the approach adopted in the current investigation. It is suitable for determining the standard of flood defence in Cardiff Bay provided that the tide and river flow conditions are not correlated, and that the type of correlation can be determined and expressed in simple terms.

The fourth option is computationally intensive (requiring many thousands of hydrodynamic simulations) but is the only method that can readily incorporate significant correlation between high tidal levels and river flood flows.

\subsection{Assumptions}

The following simplifying assumptions were made.

(a) High tide level coincides with the maximum river discharge into the inland bay.

(b) Tidal curves follow a standard shape from that used in the design study. ${ }^{3}$

(c) The river flood hydrograph shape follows that used in the design study. ${ }^{3}$

(d) The frequency distribution for flood discharges could be taken from the design study. ${ }^{3}$

(e) The frequency distribution for the extreme surge tides (1990 conditions) could be taken from a previous study. ${ }^{4}$

(f) The scenarios for climate change impact in future decades will be limited to a rise in mean sea level according to the current MAFF guidance $^{5}$ of $5 \mathrm{~mm} /$ year (that is, $0 \cdot 3 \mathrm{~m}$ between 1990 and 2050); river flows will not be affected.

$(g)$ The sluices in the barrage operate as designed.

(h) River flows remain within the channels of the Rivers Taff and Ely until they reach the inland bay.

(i) There is no inundation of the area around the inland bay from water stored in the bay.

The first and the final two assumptions are obviously conservative. The other assumptions are reasonable, but the degree of conservatism (or optimism) in each is unknown. An assessment of the significance of the conservatism in assumption (a) is made in the later stages of this paper. Obviously, future climate conditions are open to much speculation; the point of including a rise in mean sea level in the assessment is that it illustrates how climate impact upon flood frequency could be established for other scenarios of sea level and river flow.

\section{I.5. Methodology}

The steps in this assessment were as follows.

(a) Develop cumulative exceedance probability functions (CEPF) for tide and river flow and volume based upon observations and previous analyses from several sources.

(b) Use the JOIN-SEA software to establish the degree of correlation between flood flows and tidal levels.

(c) Generate structure functions for the maximum water level in the inland bay as a function of the hydro-meteorological forcing by using the ISIS model to simulate the interaction of the tide and river flow conditions with the operation of the sluices.

(d) Undertake numerical integration of the joint probability tides and river flows that give the water levels described by the structure functions, with and without an allowance for global warming.

(e) Consider the sensitivity of the results to the assumptions made in the analysis.

\section{RESULTS}

\section{I. Probability distribution for high tide level}

A cumulative exceedance probability function (CEPF) describes the probability that a particular event (such as high tide level) will exceed a specific value, say 7.0 m OD. The CEPF for high tide level was generated from a reconstructed tide-level sequence at Cardiff Docks based upon regression with 
Avonmouth. HR Wallingford has undertaken analyses of the frequency of tides at Cardiff Docks on several occasions. The previous work ${ }^{6}$ on this record was updated with the latest correlation between the two sites. The CEPF used the observed tide levels up to about $7 \cdot 3 \mathrm{~m}$ OD (based upon counting the occurrence of events in a 27.75-year long daily record: 19624 tides). This count-back method used a class interval of $0 \cdot 1 \mathrm{~m}$ to estimate the tidal frequencies. Above $7 \cdot 3 \mathrm{~m}$ OD there are relatively few observations in the continuous record, and a more reliable estimate of the exceedance frequency of these surge tides was generated from the annual maximum series analysis for rarer events given in the report EX 2284. ${ }^{4}$ This analysis fitted a Gumbel (or General Extreme Value, GEV, Type 1) distribution to data from the 1920s onwards, and has been shown to be consistent with estimated extreme water levels for historically significant events in the Bristol Channel back to about 1600. From this information the cumulative exceedance frequency was calculated in $0 \cdot 1 \mathrm{~m}$ intervals for all tide levels from $1.5 \mathrm{~m}$ OD to $9.0 \mathrm{~m}$ OD.

The frequency of flooding around the inland bay prior to the construction of the barrage was determined by the frequency of occurrence of high tides, and is thus represented by the values of return period in Table 1.

\subsection{Probability distribution for river flow}

A long digital data series for mean daily river flow was available from the study ${ }^{2}$ in 1994 on bay level frequency. The data represent flow from the River Taff at Pontypridd and the Ely at St Fagans, with some overlapping of record. A relationship between the mean daily discharges from the Rivers Taff and Ely was developed to extend the data to account for the missing periods of data. The two flows were summed with an allowance for the ungauged catchment to produce an estimate of the mean daily flow into the bay. This record was processed to produce statistics for the daily exceedance of particular values of mean daily flow.

\begin{tabular}{|ccl}
\hline Return period: years & Water level: m OD & Method \\
\hline $0 \cdot 11$ & $6 \cdot 90$ & Count-back \\
$0 \cdot 18$ & $7 \cdot 00$ & Count-back \\
$0 \cdot 34$ & $7 \cdot 10$ & Count-back \\
$0 \cdot 82$ & $7 \cdot 20$ & Count-back \\
$2 \cdot 14$ & $7 \cdot 30$ & Count-back \\
5 & $7 \cdot 35$ & GEV \\
$6 \cdot 2$ & $7 \cdot 40$ & GEV \\
10 & $7 \cdot 50$ & GEV \\
16 & $7 \cdot 60$ & GEV \\
20 & $7 \cdot 64$ & GEV \\
27 & $7 \cdot 70$ & GEV \\
44 & $7 \cdot 80$ & GEV \\
50 & $7 \cdot 82$ & GEV \\
100 & $7 \cdot 96$ & GEV \\
122 & $8 \cdot 00$ & GEV \\
202 & $8 \cdot 10$ & GEV \\
250 & $8 \cdot 14$ & GEV \\
336 & $8 \cdot 20$ & GEV \\
560 & $8 \cdot 30$ & GEV \\
930 & $8 \cdot 40$ & GEV \\
1550 & $8 \cdot 50$ & GEV \\
& &
\end{tabular}

Table I. Frequency of extreme water levels at Cardiff Docks
A relationship between the mean daily and peak flows was produced from the record at Pontypridd, and a CEPF was developed for the combined peak flow into Cardiff Bay up to about $500 \mathrm{~m}^{3} / \mathrm{s}$. The existing GEV flood frequency analysis ${ }^{3}$ was used to determine the tail of the distribution up to the 100year return period. The frequency curve was extended to higher return periods using the Flood Studies Report ${ }^{7}$ (FSR) regional growth curve (RGC) for Wales, extrapolated linearly as far as necessary beyond the FSR 1000-year limit. Table 2 shows the final result for the frequency of peak river flow into the inland bay. Finally a simple mathematical function was developed to represent the cumulative exceedance frequency of the total peak inflow into the bay from $0 \mathrm{~m}^{3} / \mathrm{s}$ to $2200 \mathrm{~m}^{3} / \mathrm{s}$ : this function was extrapolated as necessary for larger peak flows.

2.3. Relationship between tide and river flow occurrences The independence of the data series for river flow and high tide level was assessed using the JOIN-SEA software ${ }^{1}$ resulting from research at HR Wallingford on joint probability analysis funded by MAFF. The data for the assessment consisted of flow rates measured at Pontypridd and the corresponding high tide levels measured at Avonmouth and converted to Cardiff, for a 32-year period (1960-1991). First of all, the Pontypridd river flow data were analysed and the 20 highest flow events selected. ${ }^{2}$ The nearest high tide level at Cardiff, corresponding to the extreme flow events, was then identified and paired with the appropriate flow. These pairs of flow and high tide (see Table 3) were considered as independent events and analysed with JOIN-SEA to determine the extent of correlation between the river flows and tide levels. The results of this exercise showed there to be independence (correlation coefficient of zero) between the two variables.

Although this showed that there was no correlation within the extreme events themselves it was also necessary to assess whether the tide levels occurring at the same time as the extreme flows were 'typical' levels or unusually above average. If the levels were above average, then this would provide an indication of some correlation between high flows and high

\begin{tabular}{|ccl|}
\hline $\begin{array}{l}\text { Return } \\
\text { period: } \\
\text { years }\end{array}$ & $\begin{array}{c}\text { Combined } \\
\text { peak inflow: } \\
\mathrm{m}^{3} / \mathrm{s}\end{array}$ & Method \\
\hline $2 \cdot 0$ & 440 & Count-back \\
$3 \cdot 7$ & 486 & Count-back \\
5 & 518 & Count-back \\
10 & 605 & GEV \\
25 & 710 & GEV \\
50 & 791 & GEV \\
100 & 877 & GEV \\
200 & 1010 & FSR-RGC \\
500 & 1150 & FSR-RGC \\
1000 & 1283 & FSR-RGC \\
2000 & 1415 & FSR-RGC (extrapolated) \\
5000 & 1591 & FSR-RGC (extrapolated) \\
10000 & 1723 & FSR-RGC (extrapolated) \\
20000 & 1856 & FSR-RGC (extrapolated) \\
50000 & 2031 & FSR-RGC (extrapolated) \\
100000 & 2164 & FSR-RGC (extrapolated) \\
& & \\
\hline Table 2. Frequencies of flood peak inflow to Cardiff Bay from \\
the Rivers Taff and Ely & \\
\hline
\end{tabular}




\begin{tabular}{|c|c|c|}
\hline Date & $\begin{array}{l}\text { Peak flow: } \\
\mathrm{m}^{3} / \mathrm{s}\end{array}$ & $\begin{array}{c}\text { Nearest high tide: } \\
\text { m OD }\end{array}$ \\
\hline 3-4 Dec 1960 & 850 & $5 \cdot 68$ \\
\hline 5 Dec 1972 & 276 & $5 \cdot 24$ \\
\hline I3 Nov 1974 & 249 & $6 \cdot 21$ \\
\hline 2 Nov 1977 & 335 & 4.04 \\
\hline $27 \mathrm{Dec} 1979$ & 648 & $3 \cdot 74$ \\
\hline || Mar 198| & 357 & $6 \cdot 01$ \\
\hline $22 \operatorname{Mar} 198 \mid$ & 382 & $6 \cdot 20$ \\
\hline 19 Dec 1982 & 282 & 4.75 \\
\hline $3 \operatorname{Jan} 1983$ & 311 & $5 \cdot 53$ \\
\hline 15 Oct 1983 & 405 & $2 \cdot 86$ \\
\hline $2 \operatorname{Jan} 1984$ & 332 & $5 \cdot 91$ \\
\hline 23 Aug 1985 & 250 & $4 \cdot 42$ \\
\hline 19 Nov 1986 & 447 & $5 \cdot 87$ \\
\hline 26 Mar 1987 & 419 & $4 \cdot 73$ \\
\hline $29 \mathrm{Dec} 1987$ & 395 & $4 \cdot 00$ \\
\hline 2 Jan 1988 & 382 & 4.96 \\
\hline 18 Feb 1989 & 315 & $4 \cdot 77$ \\
\hline 7 Feb 1990 & 467 & $5 \cdot 14$ \\
\hline 2 Jan |99| & 363 & $6 \cdot 29$ \\
\hline 23 Feb |99| & 289 & $3 \cdot 87$ \\
\hline 13 Dec 198I (surge event) & 15 & $7 \cdot 80$ \\
\hline 25 Feb 1990 (surge event) & 84 & $7 \cdot 81$ \\
\hline
\end{tabular}

Table 3. Recent extreme flow and water level events

tide levels at the site. The highest tide level within the sample corresponding to extreme river flows was $6 \cdot 29 \mathrm{~m}$ OD occurring on 11 March 1991 (Table 2). The analysis of over 27 years of high water levels, in section 2.1 above, shows a high tide level of $6.29 \mathrm{~m}$ to be exceeded on average approximately 50 times per year. This is therefore a relatively frequently occurring water level and cannot be considered unusual.

Following the analysis of discrete flood events, a full assessment of the joint record of mean daily flow and tide level was carried out, to confirm that the assumption of independence is valid for more common events. Mean daily flows at Pontypridd were available from the 1994 study $^{2}$ for the period from 1970 to 1987 . The mean daily flow data are averaged from 9 am to 9 am, and lose all information on the timing of the peak during the day. These flow data were combined with the Cardiff tide level data by selecting the highest tide that occurred each day. These combined data were then analysed using the JOIN-SEA software to determine the interdependence of the two variables. The results of the analysis of the full record showed a small negative correlation, which further confirmed the results of the study of the individual flood peaks and surge tides.

Additionally, the finding of independence between concurrent floods and tides is consistent with the physical argument that the meteorological conditions that cause tidal surge and river floods will lead to a time lag between peak surges and the subsequent peak river flows. This lag will be of the order of the time of concentration of the River Taff flood (about $\frac{1}{2} \mathrm{day}^{3}$ ) and thus positive correlation is unlikely unless surges occur on successive tides.

If, conservatively, independence is assumed, then there is no reason to assume that a higher than average tide would occur at the time of an extreme flow. Thus the probability of a 100year (once in 70700 tides) fluvial event combining with a one-year (once in 707 tides) water level event would then be $2 \times 10^{-8}$ on any particular high tide (assuming 707 high waters per year) or a return period of 70700 years.

\subsection{Development of the bay level structure function}

The structure function curves represent all the events that will produce the same water level in the inland bay. An existing verified ISIS model was used to examine the interaction of tides and river flow producing inland bay water levels. The model was run for approximately 230 different combinations of tide level and river flow peak. The actual combinations were chosen from a feasibility-level hand assessment to put the data from the tests in the part of the structure function diagram that was expected to contribute to the bay levels of interest. These were based upon hand interpolation and extrapolation from the data point values produced in the ISIS runs. The structure function curves are shown in Fig. 1. The contours are for water levels between 5.0 and $9.0 \mathrm{~m}$ OD in the inland bay at $0.5 \mathrm{~m}$ intervals.

\subsection{Joint probability estimation}

This integration combined the structure function curves (see section 2.4) with the exceedance frequencies (see sections 2.1 and 2.2), to produce return periods for each target water level in the inland bay $(5 \cdot 0,5 \cdot 5,6 \cdot 0,6 \cdot 5,7 \cdot 0,7 \cdot 5,8 \cdot 0,8 \cdot 5$ and $9 \cdot 0 \mathrm{~m}$ OD). This final step involved integrating the product of the two CEPFs (for tide and river flow) over all combinations that 


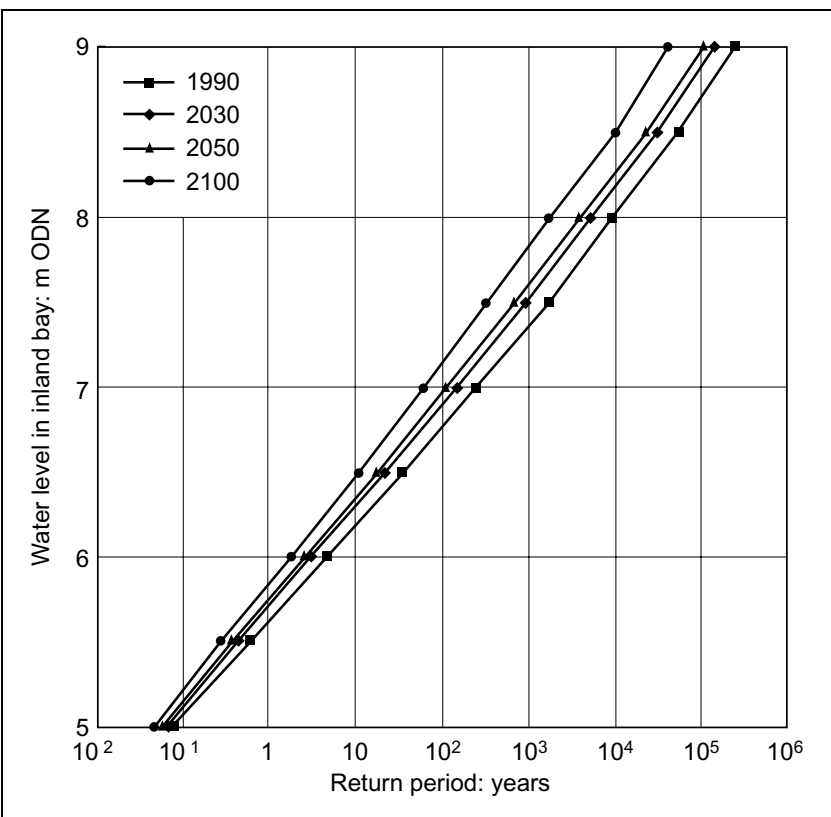

Fig. 2. Results of the joint probability analysis of the structure functions, for events that had an average peak level of $7.69 \mathrm{~m}$. In this case, however, the maximum river flow was assumed to occur at low tide. The results indicated that water levels in the bay would be reduced on average by about $0.7 \mathrm{~m}$ in this part of the structure function curves. Thus the degree of conservatism introduced by assuming that the tide and river flow peaks coincide is about $0.35 \mathrm{~m}$ at the bay level of around $7 \cdot 7 \mathrm{~m} \mathrm{OD}$.

The results of the continuous simulation analysis ${ }^{2}$ in 1994 of the reconstructed flow and tidal records are representative of the frequencies of moderate water levels in the inland bay up to the 50-year return period, since this simulation did not require the assumptions made in the joint probability (JP) analysis (see section 1.4 above). A combined frequency plot was produced by hand of these results with the joint probability results with the current conditions shifted by $0 \cdot 35 \mathrm{~m}$ for the $7 \cdot 7 \mathrm{~m}$ bay level. This represented a cautious best estimate of the frequency distribution post impoundment, taking account of the conservatism introduced by the assumptions made in the joint probability analysis. The values are given in Table 5 and are plotted in Fig. 3. The change in gradient of the frequency curve at the 50-year return period results from fitting the curve to the adjusted value at the $7 \cdot 7 \mathrm{~m}$ bay level, which still embodies a degree of conservatism.

\section{DISCUSSION}

The Barrage has substantially reduced the flood risk in Cardiff. From the conservative joint probability analysis, the frequency of exceedance of the $8.0 \mathrm{~m}$ development level in the Bay is 1 in 8000 years post-impoundment, compared with about 1 in 122 years pre-impoundment. For exceeded the target bay level. This was done numerically using an Excel spreadsheet written for the purpose. The numerical integration was undertaken in both horizontal and vertical strips and the average of the two results taken.

Repeating the joint probability estimation for future scenarios of sea level and river flow was achieved by adjusting the CEPF values by adding the allowance for rise in mean sea level to all points of the tidal CEPF, assuming that the inland bay storage and operation remains the same. The results are summarised in Fig. 2 and Table 4.

\subsection{Sensitivity tests on the assumption of coincident tide and river flood peaks}

The sensitivity of the results to the conservative assumption that tidal and river flow maxima are coincident was assessed for certain conditions close to the 7.5 and $8.0 \mathrm{~m}$ structure function curves. Five ISIS runs were undertaken for combinations of tide and river flow that had been used in the derivation

\begin{tabular}{|ccl|}
\hline $\begin{array}{l}\text { Return period: } \\
\text { years }\end{array}$ & $\begin{array}{c}\text { Bay level: } \\
\text { m OD }\end{array}$ & Method \\
\hline 2 & $5 \cdot 32$ & Continuous simulation \\
5 & $5 \cdot 53$ & Continuous simulation \\
10 & $5 \cdot 66$ & Continuous simulation \\
25 & $5 \cdot 84$ & Continuous simulation \\
50 & $5 \cdot 98$ & Continuous simulation \\
100 & $6 \cdot 22$ & Adjustment of JP analysis \\
200 & $6 \cdot 45$ & Adjustment of JP analysis \\
500 & $6 \cdot 76$ & Adjustment of JP analysis \\
1000 & $7 \cdot 0$ & Adjustment of JP analysis \\
2500 & $7 \cdot 3$ & Adjustment of JP analysis \\
4500 & $7 \cdot 5$ & Adjustment of JP analysis \\
20000 & $8 \cdot 0$ & Adjustment of JP analysis \\
85000 & $8 \cdot 5$ & Adjustment of JP analysis \\
& & \\
\hline Table 5. Best estimate of frequency relationship post- \\
impoundment & & \\
\hline
\end{tabular}




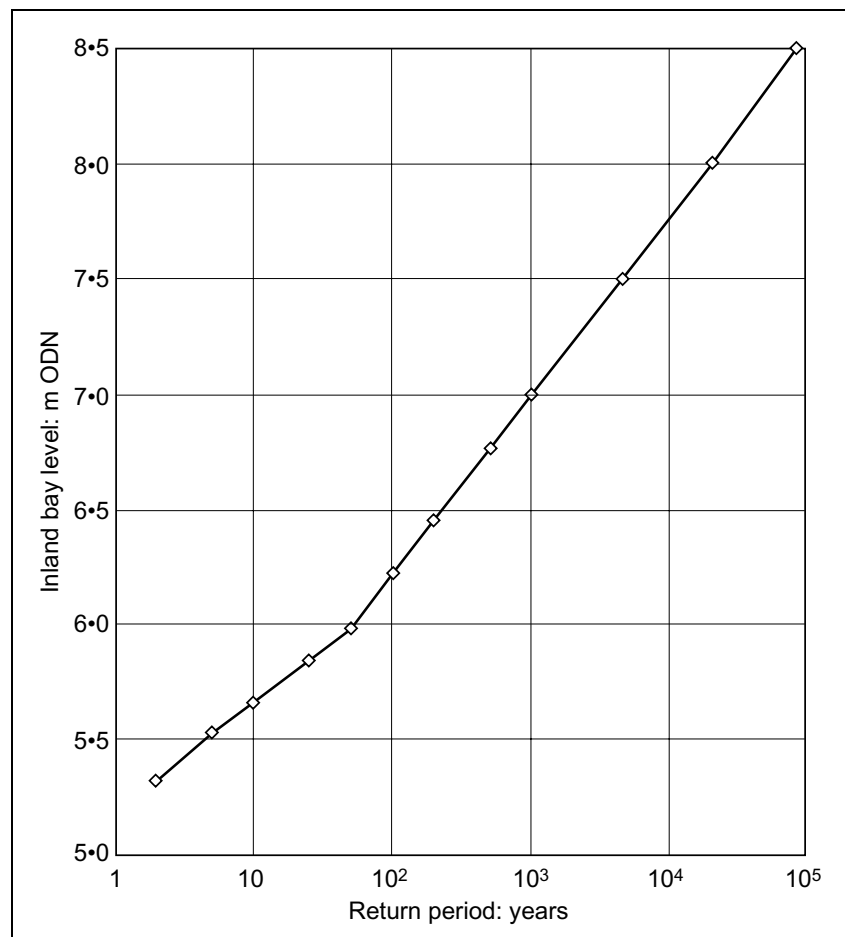

Fig. 3. Best estimate of frequency relationship (postimpoundment)

an operational still water level of $7 \cdot 3 \mathrm{~m}$ the comparison is in excess of 705 years post-impoundment compared with 1 in $2 \cdot 1$ years pre-impoundment. Even allowing for the effects of sea level rise to the year 2100, in the conservative joint probability analysis the return period of the $7 \cdot 3 \mathrm{~m}$ bay level exceeds 150 years. The return period of the $8.0 \mathrm{~m}$ level exceeds 1500 years for the 2100 scenario.

The levels quoted above from the joint probability analysis for each of the return periods post-impoundment involve some conservative assumptions, the most important being the assumption that the high tide and peak river flow are coincident. This factor gives an overestimate of level of about $0.35 \mathrm{~m}$ for water levels between 7.5 and $8.0 \mathrm{~m}$. Making adjustment for this conservatism, and tying the joint probability results into the results of the earlier continuous simulation exercise, ${ }^{2}$ leads to the estimates in Table 6 of return period for the $7 \cdot 3,7.5$ and $8.0 \mathrm{~m}$ levels in the inland bay for the scenarios with rise in mean sea level to 2100 , with return periods at 2100 for these levels of 600, 1100 and 4800 years.

By way of comparison, the indicative standard for the design of flood defences recommended by MAFF for urban areas ${ }^{5}$ is $50-$ 200 years return period for fluvial flooding and 100-300 years return period for marine flooding. By 2100 the return period of the $8.0 \mathrm{~m}$ tide will reduce from 122 years to about 5 years if mean sea level rises by $5 \mathrm{~mm} /$ year (the current allowance recommended by MAFF for the effects of global warming). Thus, without the barrage, there would be a substantial increase in flood risk around the inland bay over the next century.

For marine conditions pre-impoundment, flood hazard arises from the surge tides and wave-induced overtopping of the sea defences from the Bristol Channel. ${ }^{6}$ Post-impoundment, the waves generated in the inland bay are likely to be much smaller that the waves in the Bristol Channel because of the limited fetch in the bay. In addition, the waves in the bay are unlikely to be correlated to the bay water level because the water level in the bay arises from river flow and not from the immediate storm conditions that generate the waves. However, this degree of correlation has not been investigated.

In future, the greatest flood hazard in the waterfront area is likely to be from surge tides and storm waves overtopping the Cardiff sea defences away from the line of the barrage if these sea defences have a lower standard of protection than that provided by the barrage and inland bay.

Thus it is seen that the construction of the barrage is a significant flood defence benefit to Cardiff, which now has greater protection from flooding from the inland bay than the Thames Barrier provides for London (approximately 1000 years for the Thames). Flood risk from impoundment of the inland bay for the waterfront area remains very low even for the currently used scenarios for mean sea level rise due to global warming to the year 2100. Obviously, future climate conditions are open to much speculation; the point of including rise in mean sea level in the assessment is that it illustrates how climate impact upon flood frequency could be established for other scenarios of sea level and river flow.

Without the barrage there would have been an increasing risk of flooding from the rise in mean sea level. If the design

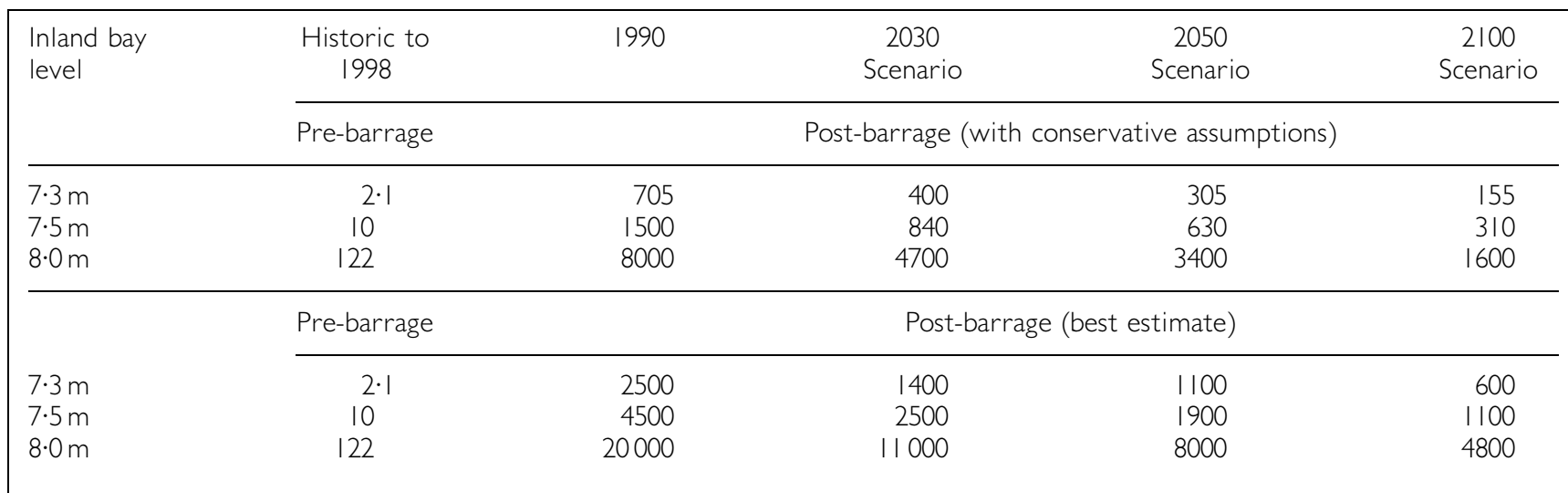




\begin{tabular}{|lllll|}
\hline Peak level: $\mathrm{m}$ & 1990 & 2030 Scenario & 2050 Scenario & 2100 Scenario \\
\hline $7 \cdot 0$ & $2 /$ year & $14 /$ year & $19 /$ year & $38 /$ year \\
$7 \cdot 3$ & $2 \cdot 1$ years & $3 /$ year & $5 /$ year & $16 /$ year \\
$7 \cdot 5$ & 10 years & $2 \cdot 1$ years & 0.8 years & $7 /$ year \\
$8 \cdot 0$ & 122 years & 44 years & 27 years & 8 years \\
8.5 & 1550 years & 560 years & 336 years & 95 years \\
& & & & \\
Table 7. Frequencies (per year) or return periods (years) for peak still water levels in the \\
Bristol Channel at Cardiff
\end{tabular}

Further advice should be sought before this research information is applied in practice.

\section{REFERENCES}

1. HR WALLINGFORD. The Joint Probability of Waves and Water Levels. JOIN-SEA: A Rigorous but Practical New Approach. HR Wallingford, 1998, Report SR 537.

allowance of $5 \mathrm{~mm} / \mathrm{year}$ is used then the return periods of certain high water levels may be estimated from the analysis of tidal frequencies in section 2, giving the values in Table 7 . Tide levels that have an estimated return period of less than 0.5 years have been assigned frequencies in average number of times per annum. These figures do not take account of the cyclical variations of astronomic forcing for specific years, but should be considered as representative for the decade of the scenario. Without the construction of the barrage, the water level in the Bristol Channel would represent the main risk of flooding in the waterfront area.

\section{ACKNOWLEDGEMENTS AND DISCLAIMER}

This joint probability appraisal was funded from the HR Wallingford internal research programme in 1999 as an illustration of the application of JOIN-SEA to river flow and surge situations. The information given in this paper is illustrative and does not necessarily reflect the professional opinion that would be given in particular circumstances.
2. HR WALlingford. Cardiff Bay Barrage: Level-DurationFrequency Analysis of Water Levels in Cardiff Bay. HR Wallingford, 1994, Report EX 2869.

3. HR WALlingford. Cardiff Bay Barrage Design Study. Report 3b: Flow Routing. HR Wallingford, 1991, Report EX 2297.

4. HR Wallingford. Cardiff Bay Barrage Design Study. Report 3a: Extreme Still Water Levels at Cardiff. Hr Wallingford, 1991, Report EX 2284 (also issued as Report EX 2297 part 3a).

5. Ministry of Agriculture, Fisheries And Food. Flood and Coastal Defence Project Appraisal Guidance, FCDPAG3: Economic Appraisals. MAFF Publications, London, 1999, Document Ref. PB4650.

6. HR Wallingford. Cardiff Bay Barrage Design Study. Report 1b: Joint Probability of Extreme Sea Levels and Severe Wave Action. HR Wallingford, 1991, Report EX 2175.

7. NERC. Flood Studies Report. Natural Environment Research Council, London, 1975 (with 18 supplementary reports issued by the Institute of Hydrology, Wallingford).

Please email, fax or post your discussion contributions to the secretary by 3 January 2003: email: lyn.richards@ice.org.uk; fax: +44 (0)20 7799 1325; or post to Lyn Richards, Journals Department, Institution of Civil Engineers, I-7 Great George Street, London SWIP 3AA. 